\title{
Valorizando a manifestação político-religiosa e cultural da Associação Terno do Congo Nossa Senhora do Rosário em Areado-MG ${ }^{1}$
}

\author{
Natalino Neves da Silva² \\ Ana Márcia da Silva Costa ${ }^{3}$
}

\section{Resumo}

Este texto é resultado de uma pesquisa de Iniciação Científica que integrou o projeto UBUNTU/NUPEAAs - Núcleo de Estudos Africanos, Afro-brasileiros e da Diáspora - da Secretaria de Estado de Educação de Minas Gerais (SEEMG), realizada no ensino médio em uma escola estadual, localizada no município de Areado, no Sul de Minas Gerais. Buscou-se investigar como a história e cultura da população negra na região são valorizadas por meio do trabalho realizado pela Associação Terno do Congo Nossa Senhora do Rosário. A perspectiva da abordagem da história oral norteou a realização metodológica do estudo. Os resultados alcançados revelam à importância de se trabalhar a valorização da cultura afro-brasileira com os(as) estudantes inseridos nesse nível de ensino.

Palavras-chave: Congada; Educação das Relações Étnico-Raciais; Ensino Médio.

\section{Valuing the political-religious and cultural manifestation of the Associação Terno do Congo Nossa Senhora do Rosário em Areado-MG}

\section{Abstract}

This text is the result of a Scientific Initiation research that was part of the project UBUNTU/NUPEAAs - Center for African, Afro-Brazilian and Diaspora Studies - of the Minas Gerais State Department of Education (SEE-MG), high school in a state school located in Areado, southern Minas Gerais. We sought to investigate how the history and culture of the black population in the region are valued through the work done by Associação Terno do Congo Nossa Senhora do Rosário of Areado-MG. The perspective of the oral history approach guided the methodological realization of the study. The results achieved revealed the importance of working to value the Afro-Brazilian culture with the students inserted in this level of education.

Keywords: Congada; Ethnic-Racial Relations Education; Secondary Education.

\section{Considerações iniciais}

Este texto é resultado de uma pesquisa de Iniciação Científica (IC) no ensino médio realizada de maneira colaborativa entre docente, discentes, gestão escolar, entre outros, contando com a participação ativa da comunidade escolar da Escola Estadual João Cândido 4

\footnotetext{
${ }^{1}$ A Fundação de Amparo à Pesquisa do Estado de Minas Gerais (FAPEMIG) financiou a realização desta pesquisa.

${ }^{2}$ Universidade Federal de Minas Gerais, Belo Horizonte, E-mail: professornatalino@gmail.com

${ }^{3}$ Escola Estadual J. L., Areado, E-mail: anamarciasilva058@gmail.com

${ }^{4}$ Por motivos éticos de pesquisa esse nome é fictício. Presta-se aqui uma homenagem a João Cândido Felisberto, também conhecido como "Almirante negro", foi um militar brasileiro da Marinha, líder da Revolta da Chibata.
} 
que se localiza no município Areado, no Sul de Minas Gerais.

A pesquisa integrou o projeto UBUNTU/ Núcleo de Estudos Africanos, Afro-brasileiros e da Diáspora (NUPEAAs) - da Secretaria de Estado de Educação de Minas Gerais (SEE-MG) cujo enfoque consistiu em introduzir a IC no ensino médio, relacionada à valorização, reconhecimento e respeito da cultura afro-brasileira e africana.

O projeto UBUNTU/NUPEAAs ${ }^{6}$ teve em vista implementar o ensino de História e Cultura Afro-brasileira e Africana, conforme previsto na Lei no. 10.639/037 e no Parecer CNE/CP no. 003/2004 e na Resolução CNE/CP n‥ 001/2004, que institui Diretrizes Curriculares Nacionais para a Educação das Relações Étnico-Raciais e para o ensino da História e Cultura Afrobrasileira e Africana (DCNERER).

O projeto foi selecionado por meio de Edital de Seleção em que seria necessário abordar perspectivas políticas e socioculturais da história africana e afro-brasileira ${ }^{8}$. 0 pioneirismo do projeto UBUNTU/NUPEAAs como uma política de ação afirmativa voltada para promover a igualdade racial na educação básica, foi formulado e constituído nos anos de 2015 e 2017, sendo que o prazo de duração dos projetos selecionados para realizar a pesquisa seria de 10 meses do ano de 2018 (CUNHA et al., 2018).

Partindo do eixo formativo ${ }^{9}$ a construção e fortalecimento das identidades afrodescendentes na contemporaneidade conforme previsto no Edital, o recorte de pesquisa privilegiou o estudo de valorização da cultura afro-brasileira local. Então para realizar a pesquisa buscou-se integrar conhecimentos plurais no sentido de contar com a participação de

\footnotetext{
${ }^{5}$ O projeto UBUNTU/NUPEAAs é uma das ações da Campanha "Afroconsciência: com essa história, a escola tem tudo a ver" lançada pela Secretaria de Estado de Educação de Minas Gerais, em 2015, que teve como objetivo promover a Educação para as Relações Étnico-Raciais no ensino médio das escolas estaduais do Estado de MG.

${ }^{6}$ A Fundação de Amparo à Pesquisa do Estado de Minas Gerais (FAPEMIG), o Instituto Unibanco, a Organização Não Governamental (ONG) Ação Educativa e diferentes Instituições de Ensino Superior (IES) foram principais interlocutores para a execução deste projeto.

${ }^{7}$ A Lei 10.639 alterou a Lei de Diretrizes e Bases da Educação Nacional (LDBEN 9.394/96) que passou a vigorar acrescida dos artigos: Art. 26-A, Art. 79-A (Vetado) e o Art. 79-B, a qual prevê a obrigatoriedade do ensino sobre a História e Cultura Afro-brasileira e Africana na educação básica ofertada nos estabelecimentos de ensino públicos e particulares. Essa Lei foi alterada em 2008 pela Lei no. 11.645 passando a incluir a História e Cultura dos Povos Indígenas Brasileiros. Neste artigo, abordamos a perspectiva da educação das relações étnico-raciais. Disponível em: http://www.planalto.gov.br/ccivil_03/_ato2007-\%202010/2008/lei/11645.htm. Acesso em: 25 mai. 2015.

${ }^{8}$ As perspectivas analíticas para a submissão do projeto foram: Cultura, memória e ancestralidade; Construção e fortalecimento das identidades afrodescendentes na contemporaneidade; Participação social, comunitária e política de combate ao racismo e discriminação racial; Africanidades, Ciências, Engenharias e Tecnologias.

${ }^{9}$ O NUPEAAs constou dos seguintes eixos formativos: cultura, história, trajetórias político-sociais e científicas dos africanos e descendentes em diáspora.
} 
professor-tutor universitário, docentes da educação básica, discentes pesquisadores(as) ${ }^{10}$, gestão e comunidade escolar, entre outros.

No diálogo em sala foi possível identificar que alguns dos discentes eram integrantes da Associação Terno do Congo Nossa Senhora do Rosário (ATCNSR), a qual há vários anos tem uma atuação político-religiosa e cultural de resistência e preservação do patrimônio imaterial da cultura afro-brasileira. Porém, nem sempre eles(as) ficavam à vontade para falar abertamente sobre a sua participação e de seus vínculos de parentesco com integrantes da Associação na sala de aula.

Partindo dessa constatação, realizou-se a seguinte indagação: como valorizar as intervenções sociais, políticas, econômicas e culturais da população negra ${ }^{11}$ na região de Areado-MG com base no conhecimento de suas histórias e tradições?

Nesse caso, a proposta de envolver os(as) estudantes participantes na realização da pesquisa, de maneira voluntária no âmbito do ensino médio, se constituiu enquanto uma propícia oportunidade, em primeiro lugar, de conhecer melhor a realidade social em que eles e elas vivem. E em segundo lugar, com vista a contribuir no combate do racismo, das discriminações e dos preconceitos raciais que repercutem tanto na sociedade como também na escola.

Dessa forma, a IC foi concebida com o objetivo de valorizar a manifestação políticoreligiosa e cultural da ATCNSR. A realização do estudo nos colocou em contato com o trabalho de revisão histórica "tradicional" que, infelizmente, ainda hoje, retrata a história da população negra apenas associada ao processo de escravidão. Daí a importância investigativa de práticas culturais locais que põem em relevo as manifestações de resistência da cultura negra de maneira articulada aos conhecimentos dos estudantes da escolaridade média.

O trabalho desenvolvido revelou os benefícios de se adotar a IC como parte integrante do processo de ensino-aprendizagem no âmbito da educação básica (DEMO, 2006). No caso específico da escolaridade média, isso foi demonstrado a partir do envolvimento, da participação e do protagonismo juvenil na realização e execução das atividades propostas.

\footnotetext{
${ }^{10}$ A IC só foi possível de ser realizada devido a participação dos(as) jovens estudantes do 3o ano do ensino médio: Alisson Luiz da Silva, Ângelo Davi Scobim, Blendel de Souza Martins, Cassielly E. Souza Costa, Eduarda Cristina de Oliveira, João Lucas Lourenço de Faria, Kaleb Romero Silva, Luciana Soares Raimundo, Maria Eduarda de Paula e Souza, Renata Maria de Lima Nogueira, Renato Garcia Jales, Ygor Expedito Gonçalves.

${ }^{11}$ A categoria "negro" é entendida por pessoas que se autodeclaram como pretas e pardas de acordo com a autoclassificação adotada pelo Instituto Brasileiro de Geografia e Estatísticas (IBGE).
} 
Os diálogos com o mundo juvenil buscaram romper com distâncias cognitivas, afetivas e sociais historicamente edificadas na relação entre discentes e docentes, conforme apontam as investigações científicas da área (SPÓSITO, 1999; DAYRELL, 2007; SILVA, 2019).

A construção do processo de ensino-aprendizagem se deu de maneira compartilhada, buscando diminuir o peso das hierarquias sociais existentes nas relações estabelecidas. Nesse caso, a Educação das Relações Étnico-Raciais (ERER) mais do que um conhecimento transmitido, foi sendo gradativamente constituído por meio de consultas, leituras e convívio com os integrantes da ATCNSR.

A realização da IC possibilitou os(as) estudantes tomarem conhecimento da luta e resistência da ATCNSR que, por meio de um trabalho secular, vem buscando preservar o patrimônio imaterial afro-brasileiro na cidade de Areado-MG.

\section{Percursos metodológicos de pesquisa}

Após a seleção dos projetos aprovados, ocorreu na capital mineira um curso de formação de professores(as); supervisores(as) regionais, inspetoras, gestores(as), equipe técnica da SEEMG e representantes da sociedade civil voltado para "Aplicação das Metodologias Participativas

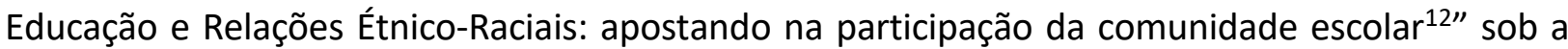
responsabilidade da Ação Educativa, durante o segundo semestre de 2017.

A base da proposta metodológica de trabalho versava sobre construir

um ambiente escolar favorável à promoção da corresponsabilidade e à definição de um conjunto de ações planejadas coletivamente que possam contribuir de forma mais sistemática para o enfrentamento do racismo, em suas articulações com as desigualdades de gênero, renda, orientação sexual, área (urbana, rural ou florestal) (CARREIRA; SOUZA, 2013, p.8).

\footnotetext{
${ }^{12} \mathrm{O}$ curso realizado pela Ação Educativa juntamente com o programa Nossa Escola Pesquisa Sua Opinião (Nepso), em parceria com a Superintendência de Modalidades e Temáticas Especiais trabalharam com os fundamentos e proposta metodológica da Coleção Educação e Relações Étnico-Raciais: apostando na participação da comunidade escolar que é composta dos seguintes materiais: Afro-brasilidades em imagens: conjunto de nove cartazes produzidos por artistas plásticos; Indicadores de Qualidade na Educação - Relações Raciais na Escola: consiste em um instrumento de apoio a processos de autoavaliação participativa escolar; 2 DVDs que buscam sensibilizar estudantes, profissionais de educação e familiares a respeito da temática da cultura Africana e Afro-brasileira e o Guia Metodológico: aborda as possibilidades de trabalhar com os materiais da coleção para diferentes contextos escolares.
} 
Partindo dessa premissa, a realização da proposta metodológica foi organizada com base no "triângulo conceitual", em cujo centro encontra-se uma gestão democrática ampla, plural e diversa, que tem como princípio o Estado de Direito. A centralidade da gestão democrática se articula de maneira indissociável com os seguintes vértices: valorização da cultura e da história africana e afro-brasileira; currículo contextualizado, plural e significativo e educação antirracista e não discriminatória.

Buscando satisfazer essa orientação metodológica, houve concomitantemente um estudo dos Indicadores da Qualidade na Educação ${ }^{13}$, por parte da equipe de pesquisadores(as), com intenção de realizar um diagnóstico da situação em que se encontrava cada instituição de ensino participante em relação à temática das relações étnico-raciais.

Tendo em vista o objetivo geral de compreender a manifestação político-religiosa e cultural da ATCNSR na cidade de Areado-MG, a pesquisa realizada é qualitativa, sendo que a técnica adotada se baseou na perspectiva de história oral, que é "um método de pesquisa que utiliza técnica da entrevista e outros procedimentos articulados entre si, no registro de narrativas da experiência humana" (FREITAS, 2006, p.18). As narrativas compartilhadas pelos sujeitos integrantes da ATCNSR constituíram nesse caso um rico acervo biográfico e ao mesmo tempo histórico.

Outras 2 (duas) etapas fizeram parte do procedimento metodológico, a saber:

a) A ambientação dos discentes no tema objeto de estudo. Para tanto, foram passadas atividades para que os mesmos procurassem fatos relacionados à cultura negra de forma a encontrar materiais como livros, imagens e reportagens que tratam ou trataram do tema;

b) A prática sistemática de estudo. Um grupo de estudantes aplicou um questionário semiaberto (com vista ao registro das lembranças e vivências) ao líder da Associação e demais integrantes. Após a coleta, o material foi transcrito e analisado por meio da técnica de análise de conteúdo (MORAES, 1999), onde o grupo buscou interpretar os dados coletados e posteriormente reapresentá-lo para a concordância ou não dos sujeitos. Esta segunda etapa possibilitou o intercâmbio de conhecimentos tradicionais e escolares. Nas etapas foi possível verificar a aquisição do conhecimento mais sensibilizado para a discussão relacionada à cultura

\footnotetext{
${ }^{13}$ Todo o material da Coleção Educação e Relações Étnico-Raciais: apostando na participação da comunidade escolar está disponível em: http://www.acaoeducativa.org.br/relacoesraciais/colecao-educacao-e-relacoesraciais/. Acesso em: 09/09/2018.
}

Periódico Horizontes - USF - Itatiba, SP - Brasil - e021012 
negra sobretudo no que diz respeito às questões relacionadas ao racismo, o preconceito e a discriminação racial.

A divulgação dos resultados obtidos foi realizada das seguintes formas: redes sociais ${ }^{14}$, uma série de palestras para discentes da própria instituição, a realização de seminários interescolares ${ }^{15}$ nas escolas municipais da cidade, registros físicos (produção de cartazes, fotos, vídeos etc.) que contribuíram para o desenvolvimento e formação de discentes com vistas a combater o preconceito e a discriminação racial no sentido de difundir esse conhecimento para além da sala de aula, e à elaboração de uma cartilha entregue aos membros da ATCNSR. Esse registro histórico objetivou atender uma reivindicação dos próprios integrantes da ausência de registro de sua manifestação político-religiosa e cultural realizada na cidade.

\section{Situando o contexto social de realização da pesquisa}

A congada é a raiz da minha vida, e graças a Deus essa raiz está viva. E só vai morrer depois que eu for! Sr. Pedro Leonel, Capitão da congada e membro mais velho atuante da ATCNSR.

A E. E. João Cândido está localizada no município de Areado-MG, que conta com uma população estimada de 13.731 habitantes. A escola oferece os últimos anos do ensino fundamental e ensino médio. $O$ atendimento é feito em três turnos, isto é, das $7 \mathrm{~h}$ às $11 \mathrm{~h} 30 \mathrm{~min}$, das $13 \mathrm{~h}$ às $17 \mathrm{~h} 30 \mathrm{~min}$. e das $19 \mathrm{~h}$ às $22 \mathrm{~h} 30 \mathrm{~min}$.

No turno da manhã são atendidos estudantes matriculados no Ensino Fundamental residentes na zona rural e ensino médio, devido à pactuação celebrada entre a Prefeitura Municipal quanto ao uso do transporte. No turno da tarde são atendidos os discentes do Ensino Fundamental. Já no noturno são ofertados para jovens, a Educação de Jovens e Adultos (EJA) e o curso Normal com habilitação para professor de Educação Infantil.

A escola tem priorizado, no seu plano de ação, o compromisso com o desenvolvimento integral do estudante, dentro do contexto social, cultural e pedagógico. Propõe ser uma escola

\footnotetext{
${ }^{14} \mathrm{O}$ grupo de pesquisa criou uma homepage no Facebook disponibilizando todas as informações de pesquisa, bem como o trabalho do ATCNSR.

${ }^{15}$ O Seminário é uma troca de experiência entre os projetos realizados em escolas estaduais propostos pela SEE-MG.
} 
viva, dinâmica e participativa, centrada na condição de que o discente é capaz de aprender, combater qualquer forma de discriminação e reconhecer seu poder de agente transformador da sociedade.

No ano de realização, a IC foi formada, além da docente supervisora, por doze estudantes dos terceiros anos. Realizar a pesquisa cientifica nesse nível de ensino se revelou de grande importância para a produção de conhecimento, para o crescimento e enriquecimento dos discentes.

Sendo assim, incentivar os estudantes a participarem de IC, pode contribuir inclusive para continuidade dos estudos no ensino superior ou técnico ou para familiarizar os procedimentos metodológicos de pesquisa.

\title{
ATCNSR do munícipio de Areado-MG
}

\author{
É de lei e é de Vera \\ É de lua é de luar \\ Uma legião de negro velho \\ Vem me visitar \\ Trazendo São Benedito e a Senhora do Rosário. \\ Sérgio Pererê. Velhos de Coroa
}

A manifestação político-religiosa e cultural da ATCNSR foi considerada, nessa pesquisa, como patrimônio imaterial das tradições culturais afro-brasileiras, pois, afinal, "na estrutura ritual das cerimônias de Reinado, a Rainha e os Reis Congos representam as nações negras africanas, hierarquicamente presidindo, na ordem do sagrado, os ritos e as celebrações ali dramatizadas" (MARTINS, 1997, p.32).

A realização das atividades da Associação é fruto, portanto, de resistência histórica, sobretudo por parte de seus membros integrantes a fim de manter e preservar as tradições transmitidas por diferentes gerações. Nesse sentido, elegemos: a valorização do patrimônio imaterial da cultura negra, a memória e o enfrentamento da discriminação e do preconceito racial como as principais categorias analíticas para desenvolver a reflexão do trabalho.

No que concerne à memória, as atividades da congada nas diferentes cidades dessa região advêm de longa data e, nesse caso, levanta-se 
a tese do negro sul-mineiro [e consequentemente a origem dessas manifestações] ter vindo de Vila Rica e de outras cidades de exploração do ouro. Tudo leva a crer que os negros aqui radicados, [trouxeram] os costumes desses centros mineradores e familiarizados com as Irmandades do Rosário e o Reinado (SOUZA, 2015, p.317).

A marcante influência cafeeira exercida no século XVIII, período colonial, desenvolvida no Sul de Minas foram seguidas pela afirmação dessas manifestações oriundas de irmandades, ternos de congos e reinados.

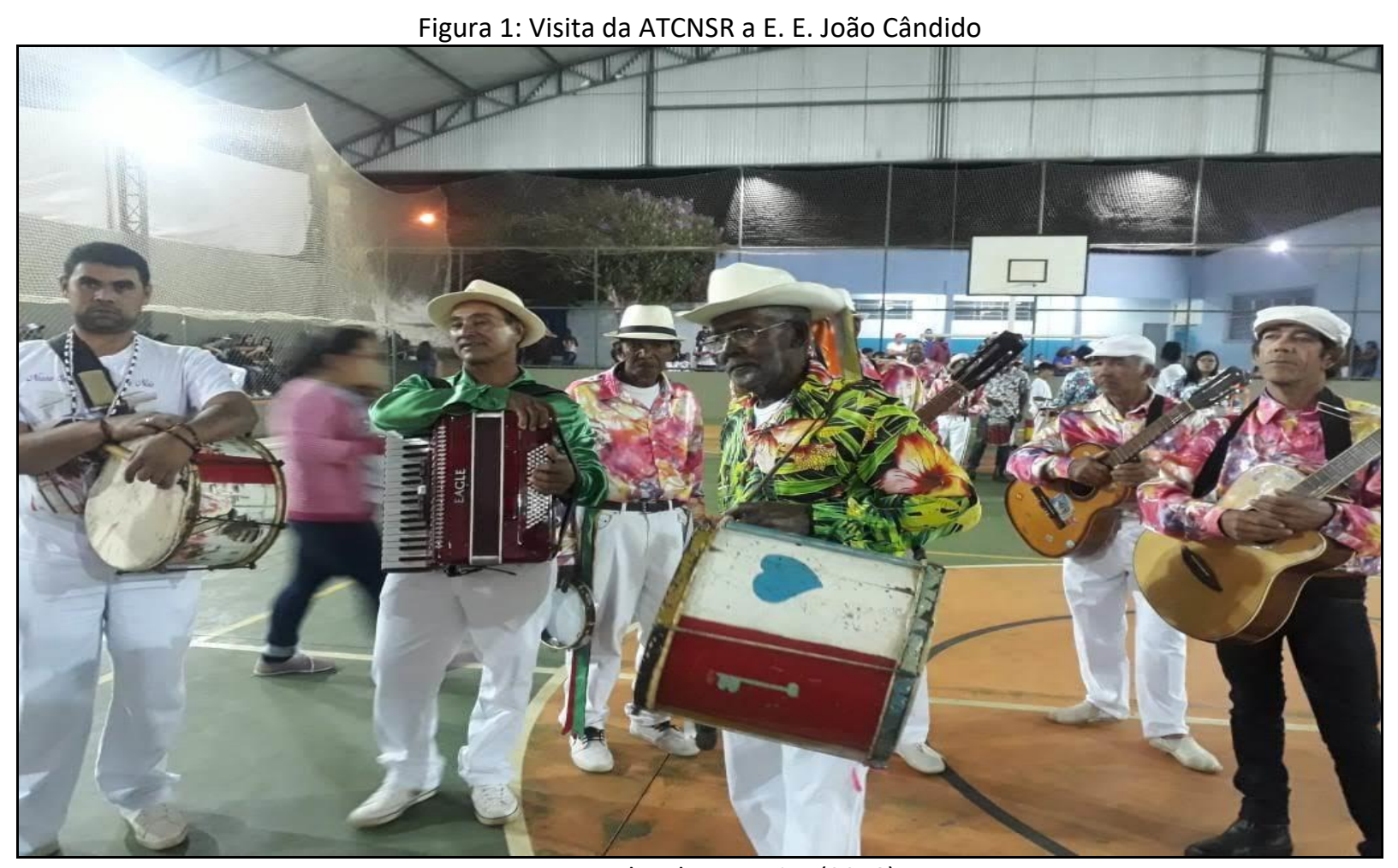

Fonte: Dados da pesquisa (2018)

O estudo desenvolvido com a ATCNSR está diretamente relacionado com o conhecimento histórico local. Todavia, nem sempre esse legado histórico é reconhecido pelos próprios moradores e órgãos governamentais. Essa constatação é evidenciada com a restrição de apoio financeiro para que a congada mantenha viva sua prática, como afirma o capitão Sr. Pedro Leonel da ATCNSR:

Ajuda com quase nada, eles ajudam é com a condução, mas verba não tem. Um tempo atrás tinha, depois que nós registramos o CNPJ, pra fazer tudo 
certinho, não recebemos mais, diziam que não tinha verba porque nós não contribuíamos. A sorte nossa é que tem gente no meio do Congado que gosta da gente, e tem umas pessoas que trabalham pra 'esses deputados' que vêm procurar a gente, que veem nesse tanto de gente a oportunidade de voto, que vêm procurar, agora nós achamos dois assim que [do mês] de janeiro em diante vai começar a dar uma ajuda pra gente (Pedro Leonel, capitão da congada, dados da pesquisa, 2018).

Para além do recurso financeiro escasso, no trabalho de campo foi possível constatar que os membros participantes da ATCNSR sofrem os efeitos do racismo estrutural ${ }^{16}$ na realização de suas ações desenvolvidas. As características de formação histórica sociocoloniais preponderantes no Sul de Minas são ainda bastante marcantes. Nesse sentido, a existência da ATCNSR por si só significa, portanto, a luta e resistência da preservação da cultura imaterial.

A ATCNSR existe desde início do século XX, pois segundo os dados coletados, é possível que o grupo tenha se formando por volta do ano de 1918, com a vinda do Joaquim Moura Leonel (avô do Sr. Pedro Leonel), que morava antes em Muzambinho-MG. Existia outro grupo de congada na cidade, porém acabou há alguns anos, como nos relata Sr. Pedro: “Meu avô era lá de Muzambinho, e aqui tinha um grupo, e ele formou o dele lá também, e o daqui acabou e o nosso continuou e nós viemos pra cá, faz mais de 100 anos que a gente vem tocando aqui" (Pedro Leonel, capitão da congada, dados da pesquisa 2018).

Praticamente todos os integrantes do terno tem algum grau de parentesco. Significa que quase todos os membros são descendentes do Sr. Pedro Leonel, integrante mais velho e capitão da congada. $\mathrm{O}$ alto grau de parentesco tem sido observado também em outros ternos e reinados (MARTINS, 1997, GOMES; PEREIRA, 2000, VIEGAS, 2014).

A esse respeito, ponderamos que a continuidade da tradição para as próximas gerações sofre os efeitos: a) vínculos afetivos, b) modernidade tardia, c) baixos investimentos financeiros de órgãos público-privados e religiosos, entre outros.

\footnotetext{
${ }^{16}$ Por racismo estrutural com Bersani $(2018$, p.193) entendemos que "corresponde a um sistema de opressão cuja ação transcende a mera formatação das instituições (...) [ele] é apropriado para manter, reproduzir e recriar desigualdades e privilégios, revelando-se como mecanismo colocado para perpetuar o atual estado das coisas". BERSANI, H. Aportes teóricos e reflexões sobre o racismo estrutural no Brasil. Extraprensa, São Paulo, v. 11, n. 2, p. 175-196, jan.-jun. 2018. Disponível em: http://www.revistas.usp.br/extraprensa/article/view/148025. Acesso em: 13 set. 2018.
} 


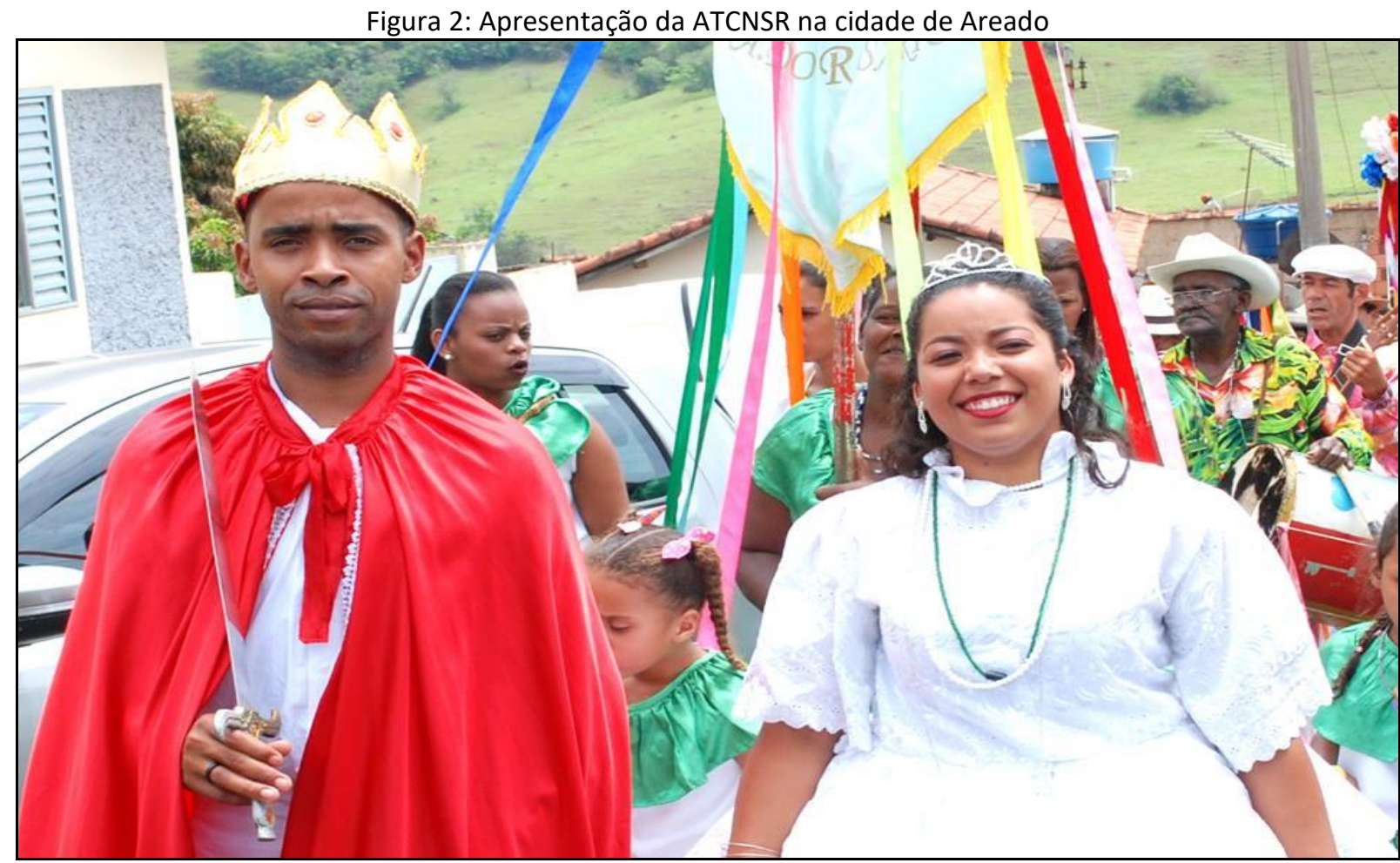

Fonte: Dados da pesquisa (2018)

Considerar a ATCNSR como sendo um patrimônio cultural imaterial da cidade contribuiria para que a população valorizasse a cultura afro-brasileira local. E mais, poderia garantir subsídios financeiros por meio das políticas públicas para que essa manifestação não desapareça como tem ocorrido em alguns locais. Nesse caso, é de fundamental importância não restringir as ações culturais apenas aos interesses secundários, conforme afirma Leal e Leal (2012, p.261):

Em todo o processo de desenvolvimento que vivemos a cultura não é tomada como algo essencial ou importante em nenhum momento. As poucas ações que acontecem são consequências de atitudes de interesses de pequenos grupos. A preocupação central é com a integração nacional, e são utilizados todos os meios para a manipulação midiática e a subordinação do povo a interesses divididos entre a preservação de hegemonias políticas e os ganhos do capital, inclusive o aplicado sobre a cultura.

O que se percebe de maneira geral é que a congada tem se mantido viva devido ao interesse de pessoas que transmitem a tradição de geração em geração. Esse quadro vem sendo lentamente alterado só nas últimas décadas, como nos diz Brettas e Frota (2012, p.31) 
“o mundo ocidental também começou a atentar para essas questões [valorização da cultura local] quando, em 1972, países orientais reivindicaram a realização de estudos para a proposição, em nível internacional, de um instrumento de proteção às manifestações populares de valor cultural".

A ATCNSR contribui para preservar o patrimônio imaterial cultural afro-brasileiro que constitui um legado histórico. Assim, Santos (2016) mostra que aos negros desafricanizados restou-Ihes construir uma cultura própria contribuindo para formação da cultura brasileira atual, ou seja, as manifestações culturais locais, como a congada, sofrem influência da cultura africana, mas contribui para formação de uma cultura brasileira, com influências dos costumes do povo brasileiro. Esse ponto de vista também é compartilhado por Silva $(2012$, p.29) ao analisar que:

Devido às transformações constantes de processos históricos e sociais, as congadas estiveram sujeitas às diversas modificações ou manutenções de sua tradição. Aceita como manifestação cultural relacionada aos negros cativos, tem em sua raiz, a oralidade e a ancestralidade norteando suas organizações, assim como a herança do universo simbólico e cultural das sociedades africanas, isto pode ser percebido através da multiplicidade da influência cultural presentes nela.

Ainda segundo a autora, as companhias de congo recriam a memória do povo africano através de narrativas místicas fazendo referência a aparição de Nossa Senhora do Rosário, das Mercês e São Benedito.

Nossa Senhora do Rosário é a santa branca e coroada que apareceu para os negros escravizados, ao lado da senzala. Segundo a tradição oral ela se compadecia do sofrimento dos cativos e derramava lágrimas que se convertiam em pétalas de rosas. Ao perceber a presença da santa os senhores construíram uma capela e para lá tentaram conduzir a sua imagem. No entanto, a cada tentativa a santa aparecia junto aos negros até que eles dançando e cantando nos ritmos do congo a carregaram para a igreja onde ela permaneceu. A aparição da santa branca para os negros no momento e local de realizações de suas danças fez de Nossa Senhora do Rosário uma divindade protetora dos congadeiros e também daqueles que respeitam e gostam do terno (SILVA, 2012, p.37).

Nesse sentido, a ATCNSR vai ao encontro das manifestações político-religiosas e 
culturais que ocorrem em todo o território nacional, uma vez que as demais companhias de congo brasileiras também reverenciam a aparição de Nossa Senhora do Rosário.

Na realização de entrevistas o grupo de estudantes passou a conhecer melhor sobre a realidade local-cultural. Isso possibilitou o exercício de romper com alguns preconceitos, uma vez que até mesmo integrantes do próprio grupo não conheciam a congada. Com isso, a realização da IC permitiu que eles(as) vivenciassem manifestações de resistências negras areadenses.

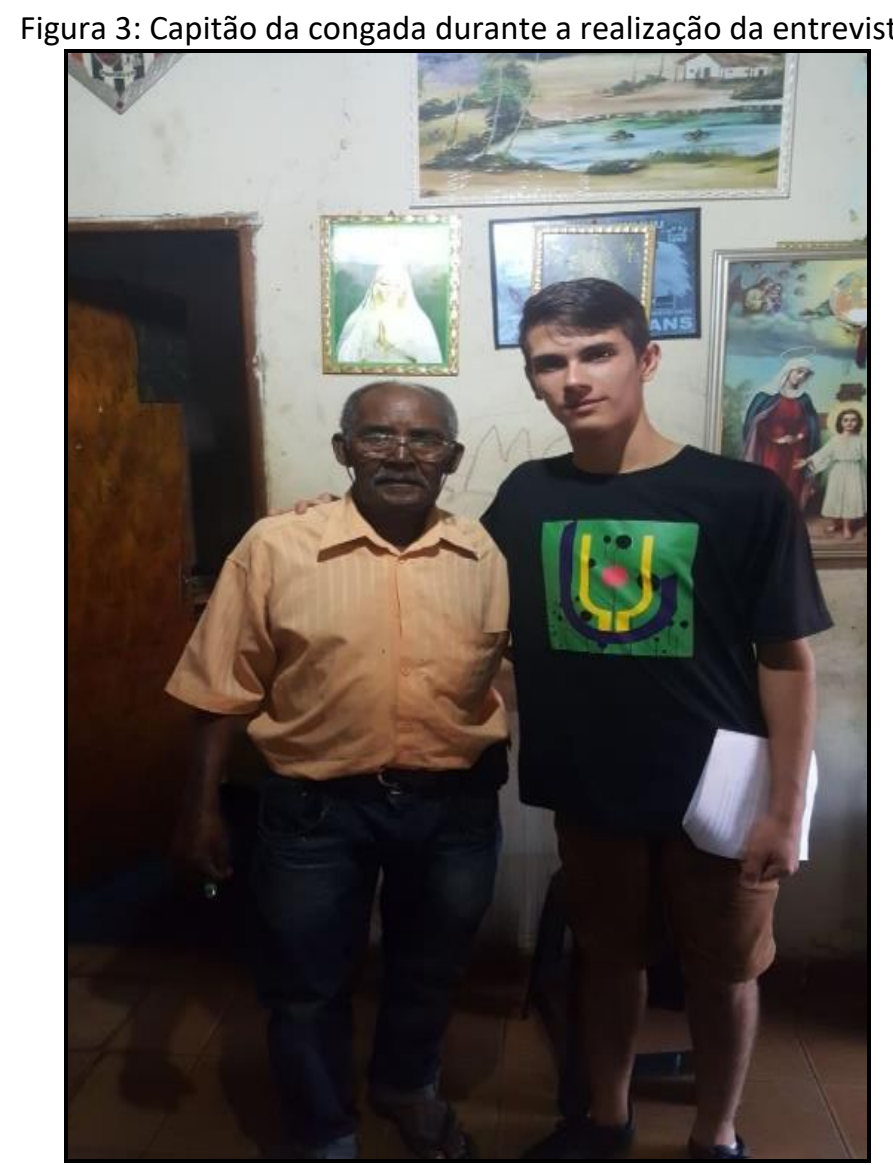

Fonte: Dados da pesquisa (2018)

Sabe-se que a organização da congada é peculiar de cada região, mas, mesmo assim, é possível perceber de forma geral que há algumas características em comum, a saber: a presença da corte, a veneração a uma santidade, a liderança do grupo, geralmente pelo capitão, entre outros.

Cada membro da congada desempenha uma função orgânica com o intuito de proporcionar ao público participante o melhor festejo possível, conforme descreve um dos 
entrevistados: "tem baterista, tem quem canta, o capitão (que é meu pai), a comissão de frente que são as meninas, depois vem outro cantador, depois vem o tarol e a bateria" (Leandro, integrante da bateria, dados da pesquisa 2018).

A esse respeito, Brettas e Frota (2012, p.36) discutem em seu trabalho sobre a organização da congada.

Enfim, são encontradas as várias categorias de figurantes e agentes que promovem a festa: os primeiros são os componentes dos grupos rituais (dançantes e capitães), e os segundos, aqueles que investem serviços e bens materiais ou financeiros. Estes últimos classificados em duas categorias: 'agentes do ritual' (capitania-geral do Congado ou coordenadores) e 'agentes da festa' (eclesiásticos, representantes do poder público, políticos e demais pessoas que doam recursos materiais e/ou financeiros para realização do evento, ou usam sua influência e prestígio pessoal para promoção do mesmo).

Sendo a cultura negra essencial para a formação cultural brasileira, a congada é uma importante manifestação político-religiosa e cultural popular afro-brasileira, nesse caso, incentivá-la e valorizá-la, torna-se necessário, ao passo que a ATCNSR enfrenta grandes dificuldades para manter a tradição viva na cidade.

Quando questionado se existe algum apoio oferecido pela Secretaria de Cultura local um integrante relata que:

[Quando a ATCNSR consegue] Transporte e alimentação. Mas não é direto não! [Por exemplo] se for mais perto [da cidade] a gente vai. Só que fica desacomodado que [o ônibus] é de sessenta lugares e não tem bagageiro. Aí tem que levar os instrumentos lá em cima. [Algumas pessoas] vão sentadas de três! Usa só um ônibus (Leandro, integrante da bateria dados da pesquisa 2018).

A partir desse e de outros relatos constatamos certo descaso por parte do poder público da cidade, quanto ao incentivo à preservação do patrimônio imaterial da cultura negra. Areado é conhecida na região como a cidade do biscoito, por isso realiza a Festa do Biscoito que conta com maior prestígio, divulgação e incentivo da população areadense, como manifestação cultural.

Uma questão que emergiu durante as conversas no grupo de pesquisa foi a seguinte: será que o fato de a congada ser uma manifestação político-religiosa e cultural visivelmente 
negra interfere no baixo investimento de recursos financeiros e no reconhecimento por parte da população?

Os relatos orais, extraídos da memória dos integrantes da ATCNSR, dão pistas de que o racismo, a discriminação e o preconceito racial permanecem vivos tanto no pensamento social quanto nas realidades institucionais. São eles que contribuem para tomar conhecimento do passado histórico sociocolonial de Areado, como afirma o capitão:

[Antes] as pessoas não se interessavam tanto, não. Não entendiam o que estava acontecendo. As pessoas vinham mais por conta da festa do Rosário, viam o Congado e achavam bonito. Eles faziam (a geração passada do Congo) umas coisas muito bonitas na porta da igreja, [em relação à] dança deles, que era bastante Congo, mas [as pessoas eram] desinteressadas. Agora nós já somos mais conhecidos. Somos muito bem recebidos nos lugares, somos chamados. Uns querem vir conhecer a nossa história! Vem aqui pra conhecer a raiz! E a boa vontade de vocês (Grupo de Pesquisa Ubuntu) em nos convidar para ir lá [na escola fazer apresentação] aquele dia foi bom demais! Ver que o povo está se importando com a história (Pedro Leonel, capitão da congada, dados da pesquisa 2018, grifos nossos).

Portanto, a realização da IC proporcionou aos estudantes e demais profissionais da educação envolvidos(as) perceber a necessidade de valorizar a manifestação político-religiosa e cultural da ATCNSR. E mais, de que o trabalho voltado para a Educação das Relações ÉtnicoRaciais na escolaridade média desafia-nos a trabalhar em uma perspectiva interdisciplinar. E de que a participação comunitária na concretização do processo de ensino-aprendizagem é de fundamental importância. Vislumbramos a partir daí possibilidades de continuidade e aprofundamento do trabalho realizado capaz de articular saberes escolares e das comunidades negras do entorno.

\section{Considerações finais}

Senhora rainha

Chega na janela

Venha ver sua guarda

Sá rainha

Eu cheguei com ela

Cântico do Congo 
A realização dessa pesquisa possibilitou aos estudantes tomarem conhecimento da luta e resistência da ATCNSR que, por meio de um trabalho secular, vem buscando preservar o patrimônio imaterial afro-brasileiro na cidade de Areado-MG.

Os diálogos realizados revelaram ainda que os membros da congada sofrem discriminação e preconceito racial por parte da população local. Ponderamos que essa atitude se dá devido a não valorização das manifestações político-religiosas das comunidades negras, pelo desconhecimento da contribuição da cultura africana e afro-brasileira e, sobretudo, em função dos efeitos do racismo estrutural verificado em nossa sociedade.

Levando em consideração as características de formação histórica sociocoloniais preponderantes no Sul de Minas a realização do estudo possibilitou-nos entender que a existência da ATCNSR por si só significa, portanto, uma expressão de luta e de resistência da preservação do patrimônio imaterial da cultura negra Sul Mineira.

Daí a importância de se trabalhar com o ensino da história e da cultura afro-brasileira conforme previsto na Lei no. 10.639/03 e das suas diretrizes no ensino médio, pois, afinal, o conteúdo tratado no âmbito escolar passou a fazer sentido para os(as) jovens negros(as) e brancos(as) envolvidos(as) na realização da investigação no que concerne à construção do conhecimento juntamente com os sujeitos da ATCNSR.

As ações desenvolvidas pelo grupo de pesquisa juntamente com a ATCNSR foram difundidas integralmente para a escola, bem como a outras instituições de ensino do entorno. $\mathrm{Na}$ divulgação dos resultados obtidos o grupo buscou valorizar a atuação da congada areadense como uma manifestação político-religiosa e cultural de resistência da região.

A criação da página da ATCNSR no Facebook com o intuito de divulgar o trabalho realizado, despertou o interesse comunitário local. Isso permitiu que os membros da congada se sentissem mais valorizados, servindo de alguma forma para evidenciar o quanto é importante à preservação e a valorização desse patrimônio imaterial.

Em suma, a abordagem das relações étnico-raciais com jovens estudantes no ensino médio só foi possível devido ao fato de que desde o início do trabalho o grupo de pesquisa constituído ter se mostrado disposto e interessado a adquirir um novo aprendizado voltado para a valorização da história e cultura afro-brasileira e africana.

De igual modo, foi importante a pesquisa ter sido acolhida pela comunidade escolar 
(docentes, discentes, gestoras da educação, serviços gerais, entre outros), bem como pela ATCNSR, no sentido de todos sermos no momento de realização do estudo aprendizes da educação para as relações étnico-raciais.

\section{Referências}

BRASIL. Lei no. 10.639, de 9 de janeiro de 2003. Altera a Lei n.9.394, de 20 de dezembro de 1996, que estabelece as diretrizes e bases da educação nacional, para incluir no currículo oficial da Rede de Ensino a obrigatoriedade da temática "História e Cultura Afro-Brasileira", e dá outras providências. Diário Oficial da União, 1ำ jan.2003. Disponível em: http://www.planalto.gov.br/ccivil_03/leis/2003/I10.639.htm. Acesso em: 13 jun. 2016.

BRASIL. Ministério da Educação. Conselho Nacional de Educação. Parecer CNE/CP no. 003/2004. Diretrizes curriculares nacionais para a educação das relações étnico-raciais e para o ensino de História e Cultura Afro-brasileira e Africana. Brasília: Ministério da Educação, 2004. Disponível em: www.acaoeducativa.org.br/fdh/.../DCN-s-Educacao-das-Relacoes-Etnico-Raciais.pdf. Acesso em: 20 nov. 2015.

BRASIL. Ministério da Educação. Conselho Nacional de Educação. Resolução CNE/CP no. 001/2004. Diretrizes curriculares nacionais para a educação das relações étnico-raciais e para o ensino de História e Cultura Afro-brasileira e Africana. Brasília: Ministério da Educação, 2004. Disponível em: www.acaoeducativa.org.br/fdh/.../DCN-s-Educacao-das-Relacoes-EtnicoRaciais.pdf. Acesso em: 20 nov. 2015.

BRETTAS, A. P; FROTA, M. G. C. O registro do Congado como instrumento de preservação do patrimônio mineiro: novas possibilidades. Revista Eletrônica do Programa de Pós-graduação em Museologia e Patrimônio, Rio de Janeiro, v.1, n.5, p.29-47, jun.2012. Disponível em: http://revistamuseologiaepatrimonio.mast.br/index.php/ppgpmus/article/viewFile/138/176. Acesso em: 25 jun. 2018.

CARREIRA, D.; SOUZA, A. L. S. Indicadores da qualidade na educação: relações raciais na escola. São Paulo: Ação Educativa, 2013.

CUNHA, A. M. et al. Articulação entre iniciação científica e promoção da igualdade racial no ensino médio: uma estratégia para políticas públicas educacionais. Revista da Associação Brasileira de Pesquisadores/as Negros/as (ABPN), v.10, p.230-242, jan.2018. Disponível em:http://www.abpnrevista.org.br/revista/index.php/revistaabpn1/article/view/538. Acesso em: 15 set. 2018.

DAYRELL, J. O jovem como sujeito social. In: SPÓSITO, M; CARRANO, P.; FÁVERO, O; NOVAES, R. (orgs.). Juventude e contemporaneidade. Brasília: UNESCO/MEC/ANPEd, 2007. p 155-178. Disponível em: https://unesdoc.unesco.org/ark:/48223/pf0000154569. Acesso em: 15 mai. 2018. 
DEMO, P. Pesquisa: princípio científico e educativo. 12. ed. São Paulo: Cortez, 2006.

FREITAS, S. M. História oral: possibilidades e procedimentos. 2. ed. São Paulo: Imprensa Oficial, 2006.

GOMES, N. P. M.; PEREIRA, E. A. Negras raízes mineiras: os Arturos. Belo Horizonte: Mazza, 2000.

LEAL, A. F.; LEAL, E. A. Políticas públicas, culturas populares e patrimônio cultural imaterial: meios e alternativas. O Espaço Geográfico em Análise, Curitiba, n.26, p.247-269, 20 ago. 2012. Disponível em: https://revistas.ufpr.br/raega/article/view/30161. Acesso em: 27 jan.2018.

MARTINS, L. M. Afrografias da memória: o reinado do Rosário do Jatobá. Belo Horizonte: Mazza, 1997.

MORAES, R. Análise de conteúdo. Revista Educação, Porto Alegre, v.22, n.37, p.7-32, 1999. Disponível em:

https://www.google.com.br/url?sa=t\&rct=j\&q=\&esrc=s\&source=web\&cd=\&ved=2ahUKEwjk6d 3S3eDpAhXBCtQKHRd7DaEQFjAAegQIAhAB\&url=https\%3A\%2F\%2Fedisciplinas.usp.br\%2Fplugi nfile.php\%2F4125089\%2Fmod_resource\%2Fcontent\%2F1\%2FRoque-

Moraes_Analise\%2520de\%2520conteudo-1999.pdf\&usg=AOvVaw0NzxZ5YQCyxQmXiCKrbb2m. Acesso em: 13 set. 2018.

SANTOS, M. Contribuição do negro para a cultura brasileira. Temas em Educação e Saúde RTES, v.12, n.2, p.217-229, jul.-dez. 2016. Disponível em:

<https://periodicos.fclar.unesp.br/tes/article/view/10229>. Acesso em: 29 set. 2018.

SILVA, C. C. Festa ou devoção? heranças imateriais da congada em diferentes regiões do Brasil. 2012. 65f. Monografia (Especialização em História) - Setor de Ciências Humanas, Letras e Artes, Universidade Federal do Paraná, Curitiba, 2012. Disponível em:

<htpp://www.humanas.ufpr.br/portal/historia/files/2012/07/Carolina-cartelli.pdf>. Acesso em: 7 ago. 2018.

SILVA, N. N. Qual é o valor do ensino médio? Experiência social e escolar de jovens negros(as) e brancos(as). Curitiba: Appris, 2019.

SOUZA, M. J. Reinado e poder no sul das Minas Gerais. Belo Horizonte: Mazza, 2015.

SPÓSITO, M. P. Educação e juventude. Educação em Revista, Belo Horizonte, n.29, p.7-13, jun.1999. Disponível em: http://educacaoemrevistaufmg.com.br/edio-anterior/educacao-emrevista-no-29-ano-1999/. Acesso em: 20 mai. 2018.

VIEGAS, M. I. O enigma do rosário: os mistérios da (r)existência nas correntezas da urbanização. 2014. 485f. Tese (Doutorado em Geografia) - Instituto de Geociências, Universidade Federal de Minas Gerais, Belo Horizonte, 2014. Disponível em: 
http://www.bibliotecadigital.ufmg.br/dspace/handle/1843/IGCC-9QJSHR. Acesso em: 15 jun.2018.

Recebido em dezembro 2019.

Aprovado em janeiro 2021. 